\title{
Some Results on Foreign Equity Portfolio Risk Backtesting via Lévy Ordinary Copula Model
}

\author{
Kresta Aleš, Tichý Tomás
}

\begin{abstract}
The soundness of risk monitoring and measuring systems is a key point for the reliability of financial institutions. One of the features of a reliable risk model is that it passes a backtesting procedure - a comparison of the one step ahead risk estimation and a true loss occurred on a given day - without any troubles. Within this paper, basic tests to backtesting procedure due to Kupiec, Christoffersen and Haas are applied on a portfolio sensitive to equity and FX rate risk. In particular details, we focus on NIG model and its variants due to various time spans used for parameter estimation. We document a significant improvement of such tail risk models on several portfolio positions.
\end{abstract}

Key words: backtesting, market risk, model validation, subordinated Lévy model, ordinary elliptical copula function.

\section{INTRODUCTION}

Financial risk modeling and its subsequent management is a very important and no less challenging task of quantitative units of financial institutions, such as banks, insurance companies, or securities firms. An efficient management of financial risk can increase the performance of any given entity. Generally, taking additional risk can, on average, increase the return on equity. However, considering a particular mix of stakeholders, there always exist some risk limits, which should not be exceeded. Otherwise, the business would become more risky than desired. Evidently, under standard assumption of convex utility function it would have negative impact on the entity value as perceived by a particular mix of stakeholders.

Since the standard market model based on Gaussian distribution does not describe the real market features well, several interesting alternatives to market risk modeling have been suggested. Recently, some of these alternatives have been carefully examined and tested. For example, Alexander and Sheedy (2008) assumed Gaussian/Student/GARCH/Empirical models for a simple position and Rank (2007) analyzed similar multi-position models joined by several copula functions. However, Tichý (2010) made a further contribution by analyzing the performance of ordinary elliptical copula Lévy driven models for FX rate sensitive portfolio risk estimation (i.e. the skewness and kurtosis in the marginal distribution and potentially a nonlinearity, but still symmetry in the dependency was allowed by parametrical approach).

The author applied the two most popular subordinated Lévy models - variance gamma model and normal inverse Gaussian model, though, almost the same results were provided. Since the definition of the variance gamma model is rather complicated, the evaluation of the inverse function to the distribution function (necessary for copula function usage) is very costly. Hence, in this paper we restrict ourselves to the normal inverse Gaussian model, which allows 
us to utilize an approximation to its distribution function and evaluate the model with 100000 scenarios in a reasonable time - note, that in order to test the model in line with Kupiec's (1995) and Christofersson's (1998) backtesting procedure, we need to repeat the algorithm day-by-day for more than 11 years in our case. Furthermore, we extend the analysis into internationally diversified portfolio as suggested by Kresta (2011a,b).

We proceed as follows. First subordinated Lévy models are defined. Then, the copula approach to joint distribution modeling is briefly explained and the exception tests are described. Finally, the data set consisting of four equities and FX rates is described and simulation results are provided.

\section{METHODOLOGY}

In this paper we try to examine whether the subordinated Lévy models joined by a suitable elliptical copula functions are eligible to estimate the risk of a FX-equity portfolio. Hence, we assume several distinct risk factors, i.e. a marginal (independent) distribution modeled by a special type of models allowing one to fit also the higher moments of the distribution (defined in subsection 2.1), which are coupled together by elliptical ordinary copula functions in order to get the joint portfolio distribution (defined in subsection 2.2). In order to examine the suitability of such approach for risk estimation, the VaR (i.e. risk estimation) is compared to the true observed loss on a day-by-day basis. Next, the sequence of 0 's and 1's (exceptions, i.e. model failure) is tested on (un)conditional coverage (described in subsection 2.3).

\subsection{Marginal distribution by subordinated Lévy models}

The first focus on Lévy models with jumps goes back to 1930's. The most recent and complete monographs on the theory behind and/or application of Lévy models are e.g. Applebaum (2004) or Cont and Tankov (2004). However, a subordinated Lévy model, a rather non-standard definition of Lévy models as time changed Brownian motions, goes back to Clark (1973) or even Bochner (1949).

Generally, a Lévy process is a stochastic process, which is zero at origin, its path in time is right-continuous with left limits and its main property is that it is of independent and stationary increments. Another common feature is a so called stochastic continuity. Moreover, the related probability distribution must be infinitely divisible. The crucial theorem is the LévyKhintchine formula:

$$
\Phi(u)=i \gamma u-\frac{1}{2} \sigma^{2} u^{2}+\int_{-\infty}^{\infty}\left(\exp (i u x)-1-i u x I_{|x|<1}\right)(d x)
$$

For a given infinitely divisible distribution, we can define the triplet of Lévy characteristics, $\left\{, \sigma^{2}, v(d x)\right\}$

The former two define the drift of the process (deterministic part) and its diffusion. The latter is a Lévy measure. If it can be formulated as $v(d x)=u(x) d x$, it is a Lévy density.

Let $X$ be a Brownian motion (BM). If we replace standard time $t$ in Brownian motion $X$,

$$
X(t ; \mu ; \sigma)=\mu d t+\sigma Z(t)
$$


by its suitable function $l(t)$ as follows:

$$
X(l(t) ; \theta ; \vartheta)=\theta l(t)+\vartheta Z(l(t))=\theta l(t)+\vartheta \varepsilon \sqrt{l(t)}
$$

we get a subordinated Lévy model. Due to the simplicity (tempered stable subordinators with known density function in the closed form), the most suitable candidates for function $l(t)$ seem to be either the variance gamma model - the overall process is driven by a gamma process from the gamma distribution with shape $a$ and scale $b$ depending solely on variance $\kappa, G[a, b]$, or normal inverse Gaussian (NIG) model - the subordinator is given by an inverse Gaussian process based on the inverse Gaussian distribution, $I G[1,1 / \nu]$. Hence, in the particular case of NIG model, we get . Hence, if we model a variable, which can be both positive and negative (e.g. price returns), we can proceed as follows:

$$
x(t)=\mu t-X(l(t))-\theta t
$$

so that the long-term drift is fit again.

\subsection{Copula functions}

A useful tool for dependency modeling are the copula functions, i.e. the projection of the dependency among particular distribution functions into $[0,1]$,

$$
C:[0,1]^{n} \rightarrow[0,1] \text { on } R^{n}, n \in\{2,3, \ldots\}
$$

In this paper, we restrict ourselves to ordinary copula functions. Basic reference for the theory of copula functions is Nelsen (2006), while Rank (2007) and Cherubini et al. (2004) target mainly on the application issues in finance. Alternatively, Lévy processes can be coupled on the basis of Lévy measures by Lévy copula functions. However, this approach is not necessary in our case.

Actually, any copula function can be regarded as a multidimensional distribution function with marginals in the form of standardized uniform distribution.

For simplicity, assume two potentially dependent random variables with marginal distribution functions $F_{X}, F_{Y}$ and joint distribution function $F_{X, Y}$. Then, following the Sklar's theorem:

$F_{X, Y}(x, y)=C\left(F_{X}(x), F_{Y}(y)\right)$

If both $F_{X}, F_{Y}$ are continuous, a copula function $C$ is unique. Sklar's theorem implies also an inverse relation,

$$
C(u, v)=F_{X, Y}\left(F_{X}^{-1}(u), F_{Y}^{-1}(v)\right)
$$

The formulation above should be understood such that the joint distribution function gives us two distinct information: (i) marginal distribution of random variables, (ii) dependency function of distributions. Hence, while the former is given by $F_{X}(x)$ and $F_{Y}(y)$, a copula function specifies the dependency, nothing less, nothing more. That is, only when we put both information together, we have sufficient knowledge about the pair of random variables $X, Y$.

It is therefore obvious that the $n$-dimensional subordinated Lévy model can be defined by terms of ordinary elliptical copula functions as follows: 


$$
F_{X_{1}, X_{2}, \ldots, X_{n}}\left(x_{1}, x_{2}, \ldots, x_{n}\right)=C\left(F_{1}\left(x_{1}\right), F_{2}\left(x_{2}\right) \ldots, F_{n}\left(x_{n}\right)\right)
$$

where $F_{i}\left(x_{i}\right)$ states for marginal distribution, i.e. a suitable subordinated Lévy model, which can be different for particular $i$, and $C$ is ordinary elliptical copula function.

There exist three main approaches to parameter estimation for copula function based dependency modeling: exact maximum likelihood method (EMLM), inference function for margins (IFM), and canonical maximum likelihood (CML). While for the former all parameters are estimated within one step, which might be very time consuming, mainly for high dimensional problems or complicated marginal distributions, the latter two methods are based on estimating the parameters for the marginal distribution and parameters for the copula function separately. While assuming IFM, marginal distributions are estimated in the first step and the copula function in the second one, for CML instead of parametric margins empirical distributions are used.

\subsection{Backtesting}

Within the backtesting procedure, the ability of a given model to estimate the future loses is to be tested. In the context of the market risk, the backtesting procedure can be applied on models in the form of $\mathrm{VaR}, \mathrm{cVaR}$ or even overall distribution of the losses. Loosely speaking, applying the historical data, i.e. true evolution of the market prices of financial instruments, the risk is estimated at time $t$ for time $t+\Delta t$, where $\Delta t$ is usually set to 1 business day, and compared with the true loss observed at time $t+\Delta t$. This procedure is applied for moving time window over the whole data set.

In line with the standards for bank supervision as defined within Basel II, let us assume that the risk is estimated for one day horizon, $\Delta t=1$. Denote Value at Risk of a portfolio X estimated at day $t$ for the next day $t+1$ on a given significance level $\alpha$ as $\operatorname{VaR}_{X}(t, t+1 ; \alpha)$ and the true loss observed at $t+1$ with respect to the preceding day $t$ as $L_{X}(t, t+1)$.

Within the backtesting procedure on a given time series $\{1,2, \ldots, T\}$, two situations can arise - the loss is higher than its estimation or lower (from the stochastic point of view, the equality shouldn't arise). While the former case is denoted by 1 as an exception, the latter one is denoted by zero. In this way, we get the sequence $\left\{I_{X}(t+1), \dot{a}\right\}_{\{t=1+m\}}^{\{\hat{O}-1\}}$, where $m$ is a number of data (days) needed for the initial estimation. On the sequence, it can be tested whether the number of ones (exceptions) corresponds with the assumption, i.e. $\alpha n$ (where $n=T-1-m$ ), whether the estimation is valid either unconditionally or conditionally, whether bunching is present, etc.

Kupiec's test (Kupiec, 1995) is derived from a relative amount of exceptions, i.e. whether their number is from the statistical point of view different from the assumption. A given likelihood ratio on the basis of $\chi^{2}$ probability distribution with one degree of freedom is formulated as follows:

$$
L R=-2 \ln \left[\frac{\pi_{e x}^{n_{1}}\left(1-\pi_{e x}\right)^{q_{0}}}{\pi_{o b s}^{n_{1}}\left(1-\pi_{o b s}\right)^{q_{0}}}\right]
$$

where $\pi_{\mathrm{ex}}$ is expected probability of exception occurring, $\pi_{\mathrm{obs}}$ is observed probability of exception occurring, $n_{0}$ is the number of zeros and $n_{1}$ is the number of ones. The Kupiec's test takes into account only the number of exceptions. By contrast, in order to asses whether the excep- 
tions are distributed equally in time, i.e. without any dependency (autocorrelation), we should define the time lag first: in Christoffersen (1998) it is defined as the stage, when exception at one time moment can significantly help to identify whether another exception will (not) follow on the subsequent day. Therefore, we replace the original sequence by a new one, where 01,00 , 11 or 10 is recorded. Then we have the likelihood ratio as follows:

$L R=-2 \ln \left[\frac{\pi_{o b s}^{n_{1}}\left(1-\pi_{o b s}\right)^{q_{0}}}{\pi_{01}^{n_{01}}\left(1-\pi_{01}\right)^{p_{00}} \pi_{11}^{n_{11}}\left(1-\pi_{11}\right)^{n_{10}}}\right]$

where $\pi_{i j}=\operatorname{Pr}\left(I_{t}=j \mid I_{t-1}=i\right)$ and $\pi_{o b s}=\frac{n_{01}+n_{11}}{n_{00}+n_{01}+n_{10}+n_{11}}$.

Obviously, we can evaluate these two tests together by calculating the following likelihood ratio:

$L R=-2 \ln \left[\frac{\pi_{e x}^{n_{1}}\left(1-\pi_{e x}\right)^{n_{0}}}{\pi_{01}^{n_{01}}\left(1-\pi_{01}\right)^{p_{00}} \pi_{11}^{n_{11}}\left(1-\pi_{11}\right)^{n_{10}}}\right]$

In Christoffersen test (both condition and unconditional) we are interested in testing only the lag of one day between the exceptions. Haas (2001) proposed the extension of the Kupiec time until first failure test (TUFF test). In order to employ this test, we have to calculate the times between subsequent exceptions $\{F(i)\}$ as a difference of times in which the $i$-th and $(i-1)$-th exception occurred (for the first exception we measure the time from the beginning of backtesting period). Then for $n_{1}$ exceptions Haas test is based on the following likelihood ratio:

$L R=-\sum_{i=1}^{n_{1}}\left\{2 \ln \left[\frac{\pi_{e x}\left(1-\pi_{e x}\right)^{F_{i}^{-1}}}{F_{i}^{-1}\left(1-F_{i}^{-1}\right)^{F^{-1}}}\right]\right\}$

This test statistic has chi-squared distribution with $n_{1}$ degrees of freedom.

\section{RESULTS}

The data set we consider in this study comprises of daily closing prices of four well established equity indices - Down Jones Industrial Average (DJI) from the US market, FTSE 100 (FTSE) from London (UK), Nikkei 225 (N225) from Tokyo (Japan) and Swiss Market Index (SMI) from Switzerland - over preceding 20 years (January 1, 1990 to December 31, 2009). However, the indices are denominated in four distinct currencies, in particular the US dollar (USD), British pound (GBP), Japan yen (JPY) and Swiss franc (CHF). This fact extends our data set to 8 distinct time series. Since the trading days at particular markets are not always harmonized, we had to interpolate missing data. In this way we get eight time series of 4,939 log-returns.

Basic descriptive statistics of daily log-returns are apparent from Table 1. In particular for each index and currency the minimal and maximal return, its mean (expected value), median and standard deviation and two higher moments, the skewness and kurtosis, are recorded. 
Tab. 1 - Descriptive statistics of FX rate returns. Source: Author's calculations

\begin{tabular}{|c|c|c|c|c|c|c|c|}
\hline $\begin{array}{c}\text { Time } \\
\text { series }\end{array}$ & $\begin{array}{c}\text { Min } \\
\text { return }\end{array}$ & $\begin{array}{c}\text { Max } \\
\text { return }\end{array}$ & Mean & Median & St.dev. & Skewness & Kurtosis \\
\hline DJI & $-8.201 \%$ & $10.508 \%$ & $0.029 \%$ & $0.045 \%$ & $1.100 \%$ & -0.060 & 12.042 \\
\hline FTSE & $-9.265 \%$ & $9.384 \%$ & $0.019 \%$ & $0.042 \%$ & $1.136 \%$ & -0.103 & 9.983 \\
\hline N225 & $-12.111 \%$ & $10.086 \%$ & $-0.017 \%$ & $0.004 \%$ & $1.479 \%$ & -0.248 & 7.894 \\
\hline SMI & $-8.383 \%$ & $10.788 \%$ & $0.032 \%$ & $0.082 \%$ & $1.177 \%$ & -0.127 & 9.420 \\
\hline USD & $-4.818 \%$ & $8.208 \%$ & $-0.008 \%$ & $-0.023 \%$ & $0.694 \%$ & 0.449 & 10.160 \\
\hline GBP & $-4.937 \%$ & $7.922 \%$ & $-0.012 \%$ & $-0.005 \%$ & $0.602 \%$ & 0.249 & 14.535 \\
\hline JPY & $-5.253 \%$ & $7.995 \%$ & $-0.001 \%$ & $-0.034 \%$ & $0.819 \%$ & 0.464 & 8.552 \\
\hline CHF & $-3.063 \%$ & $7.313 \%$ & $-0.004 \%$ & $-0.013 \%$ & $0.519 \%$ & 0.790 & 14.791 \\
\hline
\end{tabular}

We utilize the input data to construct positions/portfolios as follows: (i) firstly we assume investment into single stock index from the point of view of the Czech investor - that is why we always have to assume two risk drivers (stock index and particular currency), (ii) market portfolio, $\prod_{m}$, (iii) equally weighted portfolio - weight of each asset in portfolio is equal to 0.25 , $\prod_{e m}$, and (iv) portfolio with minimum variance, $\prod_{m}$. Note, that the composition of $\prod_{m}$ and $\prod_{m v}$ was estimated on the basis of the whole dataset assuming that we know the future evolution. The estimated weights of these portfolios are summarized in Table 2.

Tab. 2 - Weights of assets in portfolios. Source: Author's calculations

\begin{tabular}{|l|c|c|c|c|}
\hline \multicolumn{1}{|c|}{ Portfolio } & DJI, USD & FTSE, GBP & N225, JPY & SMI, CHF \\
\hline market portfolio, $\prod$ & $29.79 \%$ & $0.00 \%$ & $0.00 \%$ & $70.21 \%$ \\
\hline equally weighted portfolio, $\prod_{\mathrm{ew}}$ & $25.00 \%$ & $25.00 \%$ & $25.00 \%$ & $25.00 \%$ \\
\hline $\begin{array}{l}\text { portfolio with minimum vari- } \\
\text { ance, } \prod_{\mathrm{mv}}\end{array}$ & $34.25 \%$ & $11.15 \%$ & $21.62 \%$ & $32.98 \%$ \\
\hline
\end{tabular}

Evolution of particular portfolios' values is depicted in Fig. 1 (price of each asset was normalized to 1 at the beginning so that the evolution is comparable). If we compare evolutions of single stock indices from the point of view of the Czech investor we can conclude that all such investments would lose the value since the beginning of this century due to relatively strong appreciation of Czech koruna. Also we can see that market portfolio, that consist of the only two efficient assets, gains more than 200\% profit in 1991-2009. On the other hand the other two portfolios provided only $50 \%$ profit in history of almost 20 years. 

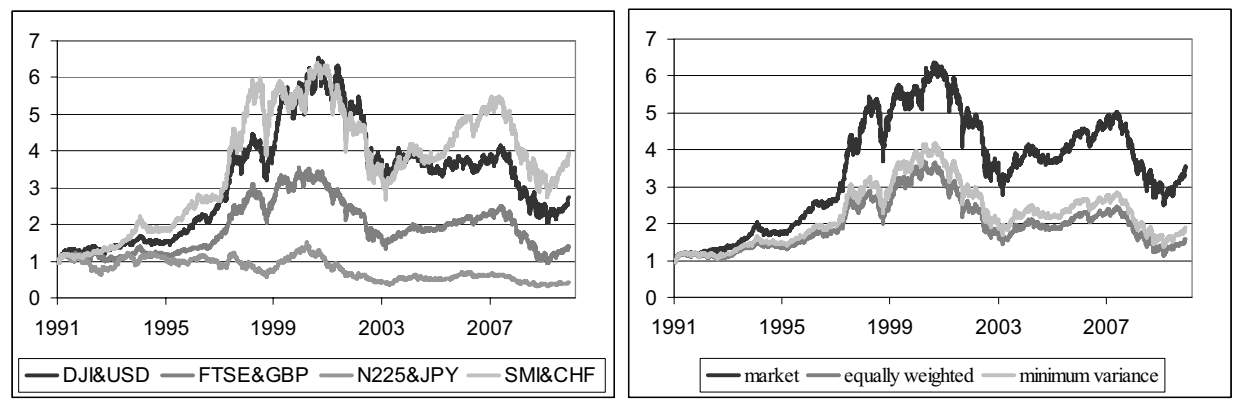

Fig. 1 - Evolution of chosen portfolios. Source: Author's calculations

\subsection{Selected models comparison}

Four distinct models will be assumed first in order to estimate the risk as given by Value at Risk measure (with significances $\alpha=0.15,0.05,0.01,0.005$ ): (i) normal distribution (Brownian motion, BM) coupled together by Gaussian copula (BM-Ga), (ii) normal distribution coupled together by Student copula (BM-St), (iii) NIG distribution coupled together by Gaussian copula (NIG-Ga) and (iv) NIG distribution coupled together by Student copula (NIG-St).

In line with subsection 2.1, the parameters of marginal distributions are estimated by means of method of moments from previous 60 observations (for NIG distribution the estimation of the kurtosis is based on previous 2000 observations) - we use the method of moments because of computing complexity of the maximum likelihood method, which makes unreasonably time requirements. Next, the CML approach was used for copula parameters estimation utilizing always 250 past observations.

Numbers of exceptions for particular models/positions\&portfolios/significances are depicted in Table 3, "winning" models are distinguished by bold font. If we take into account only the number of winning cases, the best choice is to couple NIG marginals with Student copula function, assuming that we are interested in the risk of the far tails. However, for $\alpha=5 \%$, Brownian motion, either with Gaussian or Student copula, overcome NIG models. Similarly, with $\alpha=15 \%$, NIG-Ga is better than NIG-St, while BM-St is better than BM-Ga. Hence, there is still significant impact of the tails, which might be modeled either by marginals or (artificially) by copulas. 
Tab. 3 - Number of exceptions over 1998-2009, BM-Ga/BM-St/NIG-Ga/NIG-St. Source: Author's calculations

\begin{tabular}{|c|c|c|c|c|}
\hline Portfolio & $\begin{array}{l}\text { N. of exception } \\
\qquad(\alpha=15 \%)\end{array}$ & $\begin{array}{l}\text { N. of exception } \\
\qquad(\alpha=5 \%)\end{array}$ & $\begin{array}{l}\text { N. of exception } \\
\qquad(\alpha=1 \%)\end{array}$ & $\begin{array}{l}\text { N. of exception } \\
\qquad(\alpha=0.5 \%)\end{array}$ \\
\hline Assumption & 440.85 & 146.95 & 29.39 & 14.70 \\
\hline DJI\&USD & $389 / 394 / 486 / 486$ & 155/152/171/172 & $50 / 48 / 33 / 32$ & $35 / 34 / \mathbf{1 5} / \mathbf{1 5}$ \\
\hline FTSE\&GBP & $403 / 405 / 477 / 484$ & $169 / 170 / 176 / 177$ & $55 / 53 / 31 / 32$ & $35 / 33 / 14 / 13$ \\
\hline N225\&JPY & $387 / 393 / 438 / 444$ & $145 / 147 / 146 / 147$ & $53 / 46 / 29 / 27$ & $36 / 32 / 14 / 14$ \\
\hline SMI\&CHF & $376 / 381 / 488 / 492$ & $146 / 147 / 154 / 155$ & $61 / 54 / 28 / 29$ & 41/38/12/13 \\
\hline$\prod_{\mathrm{m}}$ & $382 / 392 / 452 / 473$ & $161 / 162 / 166 / 168$ & $67 / 58 / 32 / 28$ & $40 / 33 / \mathbf{1 3} / 12$ \\
\hline$\prod_{\mathrm{ew}}$ & $401 / 419 / 444 / 467$ & $171 / 172 / 174 / 178$ & $51 / 42 / 32 / 29$ & $33 / 26 / 22 / 17$ \\
\hline$\prod_{\mathrm{mv}}$ & $412 / 427 / 452 / 470$ & $166 / \mathbf{1 6 5 / 1 7 0 / 1 7 5}$ & $57 / 49 / 32 / 27$ & $34 / 24 / 17 / 16$ \\
\hline
\end{tabular}

While the estimation of BM is very simple, when dealing with NIG model, one has to take into account information of different nature - see e.g. Kresta and Tichý (2012). Especially the kurtosis is related to rare events that by nature cannot arise frequently and are difficult to estimate within short time horizon. By contrast, the standard deviation as well as the basic measure of dependency can change suddenly, e.g. due to the regime switching.

In Table 4 and 5 we therefore provide results for BM-St and NIG-St separately according to the estimation period. In particular, we examine the time span of 30/60/250 day for the former and 60-60-2000/250-250-250/250-250-2000/250-2000-2000 days for the latter with different time span for estimation of particular moments of the distribution (different time spans are denoted as follows: mean and standard deviation-skewness-kurtosis). In contrast to Table 3, we distinguish by bold font the results, which are significant at $5 \%$ probability level according to the Kupiec's unconditional test.

Tab. 4 - Number of exceptions over 1998-2009, BM-St, estimated from 30/60/250 days. Source: Author's calculations

\begin{tabular}{|c|c|c|c|c|}
\hline Portfolio & $\begin{array}{c}\text { N. of exception } \\
(\alpha=15 \%)\end{array}$ & $\begin{array}{c}\text { N. of exception } \\
(\alpha=5 \%)\end{array}$ & $\begin{array}{c}\text { N. of exception } \\
(\alpha=1 \%)\end{array}$ & $\begin{array}{c}\text { N. of exception } \\
(\alpha=0.5 \%)\end{array}$ \\
\hline Assumption & 440.85 & 146.95 & 29.39 & 14.70 \\
\hline DJI\&USD & $\mathbf{4 5 4 / 4 2 0 / 3 9 4}$ & $\mathbf{1 7 0 / 1 4 9 / 1 5 2}$ & $52 / 55 / 48$ & $35 / 36 / 34$ \\
\hline FTSE\&GBP & $\mathbf{4 7 3 / 4 5 5 / 4 0 5}$ & $193 / 181 / \mathbf{1 7 0}$ & $53 / 49 / 53$ & $37 / 34 / 33$ \\
\hline N225\&JPY & $\mathbf{4 3 9 / 4 3 0 / 3 9 3}$ & $186 / \mathbf{1 6 2} / \mathbf{1 4 7}$ & $51 / 47 / 46$ & $28 / 33 / 32$ \\
\hline SMI\&CHF & $481 / 445 / 381$ & $180 / 179 / \mathbf{1 4 7}$ & $61 / 64 / 54$ & $37 / 46 / 38$ \\
\hline$\prod_{\mathrm{m}}$ & $491 / 452 / 392$ & $182 / 177 / 162$ & $48 / 59 / 58$ & $29 / 29 / 33$ \\
\hline$\prod_{\mathrm{ew}}$ & $\mathbf{4 6 3 / 4 5 4 / 4 1 9}$ & $192 / 182 / 172$ & $45 / 50 / 42$ & $27 / 29 / 26$ \\
\hline$\prod_{\mathrm{mv}}$ & $\mathbf{4 6 2 / 4 5 5 / 4 2 7}$ & $181 / 174 / \mathbf{1 6 5}$ & $\mathbf{3 9} / 48 / 49$ & $23 / 25 / 24$ \\
\hline
\end{tabular}

According to the results in Table 4 , it is apparent that BM is not suitable to fit the tail risk with any time span. However, if we wish to estimate the risk at $15 \%$ probability level, the most suit- 
able time span is 60 days, i.e. two months, which is given by short term nature of the volatility. By contrast, if we decide to apply the NIG model (Table 5) we can see that all considered combinations provide us significantly good estimation of the tail risk - we can say that the last combinations provide slightly better results.

Tab. 5 - Number of exceptions over 1998-2009, NIG-St, estimated from 60-60-2000/250250-250/250-250-2000/250-2000-2000 days. Source: Author's calculations

\begin{tabular}{|c|c|c|c|c|}
\hline Portfolio & $\begin{array}{l}\text { N. of exception } \\
\qquad(\alpha=15 \%)\end{array}$ & $\begin{array}{c}\text { N. of exception } \\
(\alpha=5 \%)\end{array}$ & $\begin{array}{l}\text { N. of exception } \\
\qquad(\alpha=1 \%)\end{array}$ & $\begin{array}{l}\text { N. of exception } \\
\qquad(\alpha=0.5 \%)\end{array}$ \\
\hline & 440.85 & 146.95 & 0 & 14.70 \\
\hline DJI\& & $536 / 424 / 486 / 489$ & 180/156/172/176 & $32 / 39 / 32 / 32$ & $15 / 24 / 15 / 18$ \\
\hline FTS & $517 / 425 / 484 / 484$ & $201 / \mathbf{1 6 0} / 177 / 179$ & $35 / 40 / 32 / 30$ & $21 / 18 / 13 / 17$ \\
\hline $\mathrm{N} 225$ & $485 / 420 / 444 / 446$ & $171 / \mathbf{1 4 4 / 1 4 7 / 1 5 5}$ & $29 / 31 / 27 / 35$ & $18 / 17 / 14 / 19$ \\
\hline $\mathrm{SM}$ & $534 / 43$ & 186 & $35 / 3$ & 13 \\
\hline$\prod_{\mathrm{m}}$ & $561 / 427 / 473 / 473$ & $200 / \mathbf{1 5 9} / \mathbf{1 6 8} / 175$ & $36 / 36 / 28 / 30$ & $13 / 15 / 12 / 12$ \\
\hline$\prod_{\text {ew }}$ & $517 / 405 / 467 / 466$ & 201/150/178/182 & $39 / 29 / 29 / 28$ & $15 / 19 / 17 / 20$ \\
\hline$\prod_{\mathrm{mv}}$ & $520 / 413 / 470 / 470$ & 203/152/175/177 & $36 / 30 / 27 / 31$ & $14 / 17 / 16 / 15$ \\
\hline
\end{tabular}

\subsection{Advance testing}

However, to asses the model's power more rigorously, some kind of advance test should be evaluated. In Table 6 and 7, p-values of Christoffersen conditional test are provided - once again, in bold we denote models that are statistically significant at $5 \%$ probability level. The general conclusion made on the basis of preceding tables is confirmed. Concerning the tails, NIG model - if estimated efficiently - often provides very high p-values, while BM might be accepted at much lower probability. Another interesting observation is that when particular models are applied for the portfolio with $\alpha=15 \%$, the results are very poor (compare to tails or single positions).

Tab. 6 - Christoffersen conditional test for BM-St, estimated from 30/60/250 days. Source: Author's calculations

\begin{tabular}{|c|c|c|c|c|}
\hline Portfolio & p-value $(\alpha=15 \%)$ & p-value $(\alpha=5 \%)$ & p-value $(\alpha=1 \%)$ & $\begin{array}{c}\text { p-value } \\
(\alpha=0.5 \%)\end{array}$ \\
\hline DJI\&USD & $\mathbf{0 . 5 6 / 0 . 0 9 / 0 . 1 3}$ & $\mathbf{0 . 6 / 0 . 5 3 / 0 . 6 4}$ & $\mathbf{0 . 1 7 / 0 . 1 4 / 0 . 2}$ & $\mathbf{0 . 3 5 / 0 . 3 4 / 0 . 3 7}$ \\
\hline FTSE\&GBP & $\mathbf{0 . 4 6 / 0 . 5 / 0 . 2 2}$ & $\mathbf{0 . 5 9 / 0 . 3 4 / 0 . 0 5}$ & $\mathbf{0 . 3 3 / 0 . 0 6 / 0}$ & $\mathbf{0 . 0 9 / 0 . 4 / 0 . 0 1}$ \\
\hline N225\&JPY & $\mathbf{0 . 5 4 / 0 . 5 6 / 0 . 5 9}$ & $\mathbf{0 . 3 / 0 . 4 3 / 0 . 3}$ & $\mathbf{0 . 8 2 / 0 . 2 2 / 0 . 0 4}$ & $\mathbf{0 . 4 6 / 0 . 0 6 / 0 . 0 5}$ \\
\hline SMI\&CHF & $\mathbf{0 . 4 5 / 0 . 0 3 / 0 . 0 1}$ & $\mathbf{0 . 6 3 / 0 . 3 1 / 0}$ & $\mathbf{0 . 1 7 / 0 . 0 6 / 0 . 0 9}$ & $\mathbf{0 . 0 9 / 0 . 2 / 0 . 5 1}$ \\
\hline$\prod m$ & $\mathbf{0 . 2 2 / 0 . 0 4 / 0 . 0 1}$ & $\mathbf{0 . 2 3} / 0.03 / 0$ & $\mathbf{0 . 2 4 / 0 . 7 9 / 0 . 1 4}$ & $\mathbf{0 . 2 9 / 0 . 2 9 / 0 . 0 6}$ \\
\hline$\prod e w$ & $0.02 / 0 / 0$ & $0 / 0 / 0$ & $0.03 / \mathbf{0 . 2 7} / 0.02$ & $0.02 / \mathbf{0 . 2 9 / 0 . 4 9}$ \\
\hline$\prod m v$ & $0 / 0 / 0$ & $0.04 / 0 / 0$ & $\mathbf{0 . 1 1 / 0 . 2 4 / 0}$ & $0.17 / 0.5 / 0.19$ \\
\hline
\end{tabular}


Tab. 7 - Christoffersen conditional test for NIG-St, estimated from 60-60-2000/250-250250/250-250-2000/250-2000-2000 days. Source: Author's calculations

\begin{tabular}{|c|c|c|c|c|}
\hline Portfolio & p-value $(\alpha=15 \%)$ & p-value $(\alpha=5 \%)$ & p-value $(\alpha=1 \%)$ & p-value $(\alpha=0.5 \%)$ \\
\hline DJI\&USD & $\mathbf{0 . 3 2} / 0.03 / 0.01 / 0$ & $\mathbf{0 . 3 2 / 0 . 6 7 / 0 . 4 7 / 0 . 7}$ & $\mathbf{0 . 3 9 / 0 . 3 / 0 . 3 9 / 0 . 3 9}$ & $\mathbf{0 . 6 9 / 0 . 5 2 / 0 . 6 9 / 0 . 6 3}$ \\
\hline FTSE\&GBP & $\mathbf{0 . 3 2} / 0.02 / 0.05 / 0.04$ & $\mathbf{0 . 0 8 / 0 . 0 4 / 0 . 0 5 / 0 . 0 3}$ & $\mathbf{0 . 0 7} / 0 / \mathbf{0 . 0 5} / 0.31$ & $0.01 / \mathbf{0 . 6 3 / 0 . 7 2 / 0 . 6 5}$ \\
\hline N225\&JPY & $\mathbf{0 . 5 1 / 0 . 5 3 / 0 . 5 3 / 0 . 4 6}$ & $\mathbf{0 . 6 2 / 0 . 2 5 / 0 . 3 / 0 . 4 6}$ & $\mathbf{0 . 2 9 / 0 . 3 3 / 0 . 2 5 / 0 . 4 3}$ & $\mathbf{0 . 6 3 / 0 . 6 5 / 0 . 7 / 0 . 1 1}$ \\
\hline SMI\&CHF & $0.02 / 0 / 0 / 0$ & $\mathbf{0 . 3} / 0 / 0 / 0$ & $\mathbf{0 . 0 7 / 0 . 4 5 / 0 . 2 9 / 0 . 3 1}$ & $\mathbf{0 . 7 2 / 0 . 0 9 / 0 . 0 5 / 0 . 0 4}$ \\
\hline$\prod_{\mathrm{m}}$ & $0 / 0 / 0 / 0$ & $0 / 0 / 0 / 0$ & $\mathbf{0 . 4 5 / 0 . 0 8 / 0 . 0 3 / 0 . 0 4}$ & $\mathbf{0 . 7 2 / 0 . 0 6 / 0 . 0 4 / 0 . 0 4}$ \\
\hline$\prod_{\mathrm{ew}}$ & $0 / 0 / 0 / 0$ & $0 / 0 / 0 / 0$ & $\mathbf{0 . 1 1} / 0.03 / \mathbf{0 . 4 4 / 0 . 4 6}$ & $\mathbf{0 . 0 6 / 0 . 6 1 / 0 . 6 5 / 0 . 5 9}$ \\
\hline$\prod_{\mathrm{mv}}$ & $0 / 0 / 0 / 0$ & $0 / 0 / 0 / 0$ & $\mathbf{0 . 0 8 / 0 . 3 1 / 0 . 2 5 / 0 . 3 3}$ & $\mathbf{0 . 0 5 / 0 . 0 9 / 0 . 6 7 / 0 . 6 9}$ \\
\hline
\end{tabular}

In Tables 8 and 9 in Appendix, the results obtained via Haas test are provided. However, the results are very poor and we cannot see any improvement even when changing the model or the way in which its parameters are estimated. The usefulness of this type of test therefore seems to be doubtful.

\section{CONCLUSION}

The presence of jumps and unexpected decreases (increases) in price provide very challenging task on any risk model. A common approach to evaluate the ability of the model to estimate the risk soundly is known as backtesting. The models can be tested from several points of view. In this paper we accompanied the basic test of Kupiec, which is based only on the number of exceptions, by testing their independency in time, due to Christoffersen, and then we combined these two tests into complex conclusion about the model suitability to risk measuring and managing. Apparently, we have shown that the NIG model is an ideal choice for tail risk measuring in case that an ideal combination of the estimation procedure can be identified. Here, we obtained the true number of exception as very close to the assumption, as well as we confirmed the independency of exceptions in time.

\section{Acknowledgements}

The research was supported by the European Regional Development Fund in the IT4Innovations Centre of Excellence project (CZ.1.05/1.1.00/02.0070) and furthermore supported by SP2012/2, a SGS research project of VSB-TU Ostrava. The access to the METACentrum (super)computing facilities provided under the research intent MSM6383917201 is also acknowledged.

\section{References}

1. Alexander, C., \& Sheedy, E. (2008). Developing a stress testing framework based on market risk models. Journal of Banking and Finance, 32 (10), 2220-2236. http://dx.doi.org/10.1016/ j.jbankfin.2007.12.041

2. Applebaum, D. (2004). Lévy Processes and Stochastic Calculus. Cambridge: Cambridge University Press. http://dx.doi.org/10.1017/CBO9780511755323

3. Bochner, S. (1949). Diffusion equation and stochastic processes. Proceedings of the National Academy of Science of the United States of America, 35, 368-370. http://dx.doi.org/10.1073/ pnas.35.7.368 
4. Cherubini, G., Luciano, E., \& Vecchiato, W. (2004). Copula Methods in Finance. Chichester: Wiley.

5. Clark, P. K. (1973). A subordinated stochastic process model with fixed variance for speculative prices. Econometrica, 41 (1), 135-156. http://dx.doi.org/10.2307/1913889

6. Cont, R., \& Tankov, P. (2010). Financial Modelling with Jump Processes. Chapman \& Hall.

7. Haas, M. (2001). New Methods in Backtesting. Financial Engineering Research Center. Working Paper.

8. Christoffersen, P. F. (1998). Evaluating interval forecasts. International Economic Review, 39 (4), 841-862. http://dx.doi.org/10.2307/2527341

9. Kresta, A. (2011a). Testování vybraných modelů odhadu hodnoty VaR. Ekonomická revue - Central European Review of Economic Issues 14 (3), 201-212. http://dx.doi.org/10.7327/ cerei.2011.09.05.

10. Kresta, A. (2011b). Odhad hodnoty Value at Risk lineárního portfolia aktiv pomoci kopula funkeí (Doctoral dissertation). Ostrava: VŠB-TU Ostrava.

11. Kresta, A., \& Tichý, T. (2011). Backtesting of portfolio risk in terms of ordinary Lévy copula model. In Jirčíková, E. et al. (Eds.), Finance and the performance of firms in science, education and practice. Zlín: Tomas Bata University in Zlín.

12. Kresta, A., \& Tichý, T. (2011). International equity risk modeling by NIG model. In Dlouhý, M. et al. (Eds.), Proceedings of the 29th International Conference on Mathematical Methods in Economics 2011 (401-406). Praha: Professional Publishing.

13. Kresta, A., Tichý, T. (2012). International Equity Portfolio Risk Modeling: The case of NIG model and ordinary copula functions. Finance a úvèr-Cz̧ech Journal of Economics and Finance. 61 (2), 141-151.

14. Kresta, A., Petrová, I., \& Tichý, T. (2010). Innovations at financial Markets: How to model higher moments of portfolio distribution. Actual Problems of Economics, 2 (12), 59-71.

15. Kupiec, P. (1995). Techniques for verifying the accuracy of risk measurement models. Journal of Derivatives, 3 (2), 73-84. http://dx.doi.org/10.3905/jod.1995.407942

16. Nelsen, R. B. (2006). An Introduction to Copulas. New York: Springer.

17. Rank, J. (2006). Copulas: From Theory to Application in Finance. London: Risk Books.

18. Tichý, T. (2010). Posouzení odhadu měnového rizika portfolia pomocí Lévyho modelů. Politické ekonomie, 58 (4), 504-521.

\section{Contact information}

Aleš Kresta, Tomáš Tichý

Vysoká škola báñská - Technická univerzita Ostrava, Faculty of Economics

Sokolská trída 33, 70121 Ostrava, Czech Republic

Tel: +420 597322336

E-mail:tomas.tichy@vsb.cr.

JEL Classification: G15, G21, G22 


\section{Appendix}

Tab. 8 - Haas test for BM-St, estimated from 30/60/250 days. Source: Author's calculations

\begin{tabular}{|c|c|c|c|c|}
\hline Portfolio & p-value $(\alpha=15 \%)$ & p-value $(\alpha=5 \%)$ & p-value $(\alpha=1 \%)$ & -value $(\alpha=0.5 \%)$ \\
\hline DJI\&USD & $0 / 0 / 0$ & $0 / 0 / 0$ & $\mathbf{0 . 3 8} / 0.01 / 0$ & $\mathbf{0 . 1} / 0.02 / 0$ \\
\hline FTSE\&GBP & $0 / 0 / 0$ & $0 / 0 / 0$ & $\mathbf{0 . 2} / 0 / 0$ & $\mathbf{0 . 0 7} / 0 / 0$ \\
\hline N225\&JPY & $0.04 / 0.01 / 0$ & $0.01 / 0 / 0$ & $0.05 / 0 / 0$ & $\mathbf{0 . 3 9} / 0 / 0$ \\
\hline SMI\&CHF & $0 / 0 / 0$ & $0 / 0 / 0$ & $0 / 0 / 0$ & $0.01 / 0 / 0$ \\
\hline$\prod_{\mathrm{m}}$ & $0 / 0 / 0$ & $0 / 0 / 0$ & $0.02 / 0 / 0$ & $\mathbf{0 . 0 6} / 0.01 / 0$ \\
\hline$\prod_{\mathrm{ew}}$ & $0 / 0 / 0$ & $0 / 0 / 0$ & $0.01 / 0 / 0$ & $0 / 0 / 0$ \\
\hline$\prod_{\mathrm{mv}}$ & $0 / 0 / 0$ & $0 / 0 / 0$ & $0.02 / 0 / 0$ & $\mathbf{0 . 0 6 / 0 . 4 5 / 0}$ \\
\hline
\end{tabular}

Tab. 9 - Haas test for NIG-St, estimated from 60-60-2000/250-250-250/250-250-2000/250-2000-2000 days. Source: Author's calculations

\begin{tabular}{|c|c|c|c|c|}
\hline Portfolio & p-value $(\alpha=15 \%)$ & p-value $(\alpha=5 \%)$ & p-value $(\alpha=1 \%)$ & -value $(\alpha=0.5 \%)$ \\
\hline DJI\&USD & $0 / 0 / 0 / 0$ & $0 / 0 / 0 / 0$ & $0.03 / 0 / 0 / 0$ & $\mathbf{0 . 0 6} / 0.01 / 0.02 / 0$ \\
\hline FTSE\&GBP & $0 / 0 / 0 / 0$ & $0 / 0 / 0 / 0$ & $0 / 0 / 0 / 0$ & $0 / 0 / 0 / 0$ \\
\hline N225\&JPY & $0.01 / 0 / 0 / 0$ & $0.02 / 0 / 0 / 0$ & $0 / 0 / 0 / 0$ & $\mathbf{0 . 1 4} / 0 / 0.05 / 0$ \\
\hline SMI\&CHF & $0 / 0 / 0 / 0$ & $0 / 0 / 0 / 0$ & $0 / 0 / 0 / 0$ & $\mathbf{0 . 2 2} / 0 / 0 / 0$ \\
\hline$\prod_{\mathrm{m}}$ & $0 / 0 / 0 / 0$ & $0 / 0 / 0 / 0$ & $0 / 0 / 0 / 0$ & $\mathbf{0 . 0 7} / 0 / 0 / 0$ \\
\hline$\prod_{\mathrm{ew}}$ & $0 / 0 / 0 / 0$ & $0 / 0 / 0 / 0$ & $0 / 0 / 0 / 0$ & $0 / 0 / 0 / 0$ \\
\hline$\prod_{\mathrm{mv}}$ & $0 / 0 / 0 / 0$ & $0 / 0 / 0 / 0$ & $0 / 0 / 0 / 0$ & $0 / 0 / 0 / 0.01$ \\
\hline
\end{tabular}

